\title{
Repensando a ética jornalística tradicional: posicionamentos editoriais no jornalismo feminista brasileiro contemporâneo
}

Rethinking traditional media ethics: Editorial positions in Brazilian contemporary feminist journalism

Repensar la ética periodística tradicional: Posiciones editoriales en el periodismo feminista brasileño contemporáneo

Bibiana GARCEZ

Universidade de Coimbra

Universidade de Coimbra

Chasqui. Revista Latinoamericana de Comunicación

N. ${ }^{\circ}$ 146, abril-julio 2021 (Sección Monográfico, pp. 199-216)

ISSN 1390-1079 / e-ISSN 1390-924X

Ecuador: CIESPAL

Recibido: 07-12-2020/Aprobado: 22-02-2021 


\title{
Resumo
}

Com o objetivo de compreender de que forma o jornalismo feminista se pode posicionar eticamente, este estudo analisou, através da análise textual (Fürsich, 2009, 2018), os posicionamentos editoriais de duas iniciativas jornalísticas brasileiras contemporâneas que trazem a ideia de equidade de gênero. Ainda que os textos analisados enunciem diferenças significativas nos seus posicionamentos, estes demonstram uma panóplia de abordagens possíveis que levam em conta as desigualdades de gênero e as intersecções das opressões, sem recair nas noções falhas da ética profissional da objetividade tradicional. Os resultados da análise mostram possibilidades de aproximação entre epistemologias feministas e a ética jornalística, nomeadamente com a ética do cuidado e a teoria do standpoint feminista.

Palavras-chave: objetividade jornalística; jornalismo alternativo; jornalismo feminista; epistemologia feminista

\begin{abstract}
Aiming at understanding how feminist journalism can position itself ethically, this study has analyzed, through textual analysis (Fürsich, 2009, 2018), the editorial positionings of two contemporary Brazilian journalistic outlets that bear the idea of gender equity. Even though the analyzed texts show significative differences between approaches, they also demonstrate an array of possibilities that take into consideration gender inequality and how oppressions intersect, without backsliding into failed notions of objectivity as journalistic professional ethics. The analysis results also show possibilities of approximation between feminist epistemologies and journalism ethics, namely through care ethics and feminist standpoint theory.
\end{abstract}

Key words: journalism objectivity; alternative journalism; feminist journalism; feminist epistemology

\section{Resumen}

Con el objetivo de comprender cómo el periodismo feminista puede posicionarse éticamente, en el presente estudio se propuso realizar un análisis textual (Fürsich, 2009, 2018) de las posiciones editoriales de dos iniciativas periodísticas brasileñas contemporáneas basadas en el principio de equidad de género. Aunque diferencias significativas respecto a las posiciones adoptadas se hayan desvelado en los textos, un abanico de enfoques centrados en las desigualdades de género desde perspectivas interseccionales se reveló sin necesidad de recurrir a las nociones cuestionables de la objetividad periodística como ética. Los resultados del análisis demostraron las relaciones posibles 
entre las epistemologías feministas y la ética periodística, es decir, la ética del cuidado y la teoría del standpoint feminista.

Palabras clave: objetividad periodística; periodismo alternativo; periodismo feminista; epistemologia feminista

\section{Introdução}

Ainda que nas últimas décadas as mulheres tenham conquistado maior espaço no mercado de trabalho jornalístico ao redor do mundo, lógicas de desigualdade mantêm-se patentes no exercício da profissão. Como demonstram vários estudos (Geertsema Sligh, 2018; Steiner, 2017) as jornalistas enfrentam a segregação vertical, detendo uma pequena parcela dos cargos de tomada de decisão, assim como a segregação horizontal, ficando majoritariamente restritas à cobertura de editorias de menor importância. Elas estão, também, mais sujeitas a situações de abuso, assédio e ataques, inclusive no ambiente online (Ferrier, 2018). Para além disso, no âmbito do conteúdo jornalístico, as mulheres majoritariamente não são ouvidas como fontes, especialmente como especialistas (Macharia, 2015). A representação que é feita por vezes ainda reproduz, mantendo vivos, estereótipos de gênero nocivos.

A reflexão sobre esta realidade faz-se urgente, entendendo o jornalismo como construtor das realidades (e vice-versa), e não resume-se apenas ao acesso e a representação das mulheres na profissão. O argumento de North (2009), feito ainda no fim da década passada, de que os efeitos da neoliberalização do jornalismo industrial têm efeitos generificados, parece-nos relevante até o momento atual, especialmente se pensado a partir da digitalização da atividade. No Brasil, de acordo com dados de 2012, ainda que as mulheres fossem maioria na profissão, a remuneração delas era inferior a dos homens (Pontes, 2017), uma tendência presente no mercado de trabalho de forma geral. De acordo com o relatório Global Gender Gap Report de 2020 (World Economic Forum, 2020), seguindo a taxa atual de crescimento das mulheres no mundo produtivo, a equidade de gênero só será alcançada em cem anos.

Neste cenário, torna-se essencial problematizar os sistemas em que as mulheres se inserem, após uma histórica condição de desprivilegio e exclusão-a posição de um Outro, como enfatizava Simone de Beauvoir no canônico O Segundo Sexo (2016 [1959]). Como instituição social, o jornalismo não deve ser afastado desta reflexão. De fato, segue-se esta mesma perspectiva: como argumenta Ross (2001), as mulheres ainda são vistas como "intrusas" na profissão. Dessa forma, é possível pensar no jornalismo mainstream em si como uma instituição generificada (Allan, 1998; De Vuyst \& Raeymaeckers, 2019; Jenkins \& Finneman, 2018; Lelo, 2019; Mahtani, 2005; Ruoho \& Torkkola, 2018), uma vez que mantém-se a lógica de que um determinado tipo de "feminilidade", aquela que refere aos papéis tradicionais de gênero atribuídos ao sexo feminino, 
não é compatível com a ideologia que rege o jornalismo, ao mesmo tempo em que se procede com uma normalização deste binarismo de gênero (Lobo et al., 2017).

Para Allan (1998), sair do âmbito de um jornalismo generificado implica repensar (ou abolir) a objetividade, ao que o autor acrescenta ser necessário passar a pensar sobre "a ordem da vida comum" e "refazer nossos relacionamentos com a verdade, de gerar maneiras radicalmente novas de ouvir as múltiplas vozes do mundo social" (p. 135). Isto implica uma reconfiguração da ética jornalística como um todo.

Por este motivo, e pensando na possibilidade da integração de valores feministas na sociedade, dirigimos o nosso interesse neste artigo especialmente para o jornalismo alternativo e feminista brasileiro contemporâneo, conscientes de que este recorte leva em consideração uma realidade específica. Se ojornalismo tradicional se baseia em uma ideologia que valoriza o masculino, então de que forma pode se construir (um)a abordagem feminista no jornalismo? Como uma forma de avançar na elaboração de uma resposta para esta pergunta, temos como objetivos aqui compreender de que forma os posicionamentos éticos do jornalismo feminista se relacionam àqueles adotados pelo jornalismo mainstream, assim como podem relacionar-se com epistemologias feministas.

Para tal, o presente estudo organiza-se da seguinte forma: em uma revisão bibliográfica, atentamo-nos para a norma da objetividade e a ética no jornalismo alternativo. Em seguida, para o jornalismo alternativo feminista e, encerrando o marco teórico, para as epistemologias feministas da ética do cuidado e do standpoint feminista e seus possíveis contributos para uma ética feminista no jornalismo. Em um segundo momento, propomos uma análise textual, conforme proposta por Fürsich (2009; 2018), dos posicionamentos editoriais das plataformas selecionadas para compor o corpus: a Revista AzMina e a Gênero e Número, ambas nativas digitais brasileiras. Finalmente, apresentamos algumas considerações sobre a reflexão possibilitada pela análise.

\section{A ética e o jornalismo alternativo}

Considerando o importante papel social do jornalismo, pensar na função do jornalismo nas sociedades democráticas é também pensar sobre a sua forma de agir e, assim, é refletir sobre sua a ética, sendo esta última definida por Ward (2009) como "atividade normativa que objetiva resolver problemas, integrar valores e auxiliar as pessoas a viverem corretamente, como indivíduos e como sociedades" (p. 295). Dessa forma, diferentes contextos implicam em entendimentos distintos do que deve ser considerado ético.

Em sua proposta uma organização histórica das ideologias dominantes na ética jornalística, Ward argumenta que vivenciamos atualmente o seu quinto estágio-momento marcado pelo mixed media, com "crescentes números de jornalistas cívicos e blogueiros não profissionais envolvendo-se com o jornalismo, desafiando ideias de verificação cautelosa e de gate-keeping" 
(Ward, 2009, p. 297). A discussão sobre a ética é evidentemente ampliada pela conectividade, e, por isso, o autor considera não há hoje um consenso sobre o que deve ser a ética jornalística.

Ainda assim, a objetividade, norma que figurava nos estágios anteriores, continua servindo como norma moral na condução do jornalismo mainstream. Esta não foi a norma moral adotada pelo jornalismo em toda sua história, tendo desenvolvido-se inicialmente nos Estados Unidos e depois espalhando-se para grande parte do globo (Muñoz-Torres, 2012; Schudson, 2001). O seu desenvolvimento esteve fortemente ligado com a industrialização e a profissionalização da prática, afetado por um "comercialismo agressivo" anterior, que já se colocava no mercado jornalístico estadunidense desde o século XIX (Schudson, 2001).

Para Westerståhl (1983), esta prática desdobrar-se-á nos valores de fatualidade, pautado pela verdade e relevância, e de imparcialidade, baseado no equilíbrio e no não-partidarismo e em uma apresentação neutra. No entanto, Tuchman (1972) entende a aplicação da objetividade como um "ritual estratégico" que visa a rapidez do processo e a proteção judicial das empresas jornalísticas. Os procedimentos adotados para tal, identificados pela autora, não garantem realmente uma abordagem objetiva, que seguiria os valores apontados anteriormente. De fato, desde a sua adoção, nas primeiras décadas do século XX nos Estados Unidos, a ideologia da objetividade foi criticada a nível teórico e desafiada a nível prático.

Historicamente, e principalmente a partir dos anos 1960 no contexto estadunidense com a ascensão da contracultura, assim como no período da ditadura militar no Brasil (1964-1985), o jornalismo alternativo marcou forte oposição a orientação ética da objetividade. Abarcar a multiplicidade de possibilidades desta corrente numa conceitualização geral beira o impossível, mas aqui adotamos o entendimento de Atton (2003): jornalismo ligado a noções de "responsabilidade social, substituindo uma ideologia de objetividade com evidente advocacy e práticas oposicionistas" (p. 267), que, de forma geral, opõe-se "às noções hierárquicas, centradas na elite, de que o jornalismo é um negócio” (p. 268).

Para além do conteúdo baseado em uma agenda alternativa à do jornalismo mainstream, com frequência é possível verificar formas de organização diversas (ver Harcup, 2003), o que pode ser benéfico para as mulheres (ver Acker, 1998). A prática do jornalismo alternativo, ainda que não se possa apontar para um caminho ou possibilidade única, propõe que "a autoridade não precisa ser localizada institucional ou profissionalmente; que credibilidade e confiabilidade podem ser derivadas de relatos de experiências vividas, não apenas da desassociação proposta pela reportagem objetiva; e que não há necessidade de separar fatos de valores" (Atton, 2009, p. 284). Assim, e considerando a importância dos valores feministas no âmbito deste trabalho, damos atenção a seguir ao jornalismo feminista. 


\section{Jornalismo alternativo no feminino}

A despeito da "histórica condição de desprivilégio das mulheres" (Lelo, 2019, p. 3) no jornalismo tradicional, "outra rota aberta para as mulheres jornalistas à época, como agora, era trabalhar para publicações não-mainstream" (Chambers et al., 2004, p. 23). Podemos olhar para o jornalismo feito por e para mulheres como imprensa feminista em diversas circunstâncias, em diferentes pontos do globo, em momentos históricos variados. No entanto, algumas características são transversais a todos estes contextos. Para Steiner (2019), uma delas será o "o compromisso de levar as mulheres a sério, suas vidas, suas ideias e possibilidades, bem como suas diferenças” (p. 7).

Gomes Barbosa e Varão (2018) consideram que "uma imprensa feminista se materializa na busca por direitos e em pautas que tratem das vidas das mulheres" (p. 19, itálico nosso). Para as autoras, no entanto, não basta focar-se na vida das mulheres, sendo necessário um projeto feminista de jornalismo que repense as práticas, as perguntas e os contextos. Para isto, uma abordagem ética diferente daquela adotada pelo jornalismo tradicional, será necessária.

De forma geral, podemos dizer que este jornalismo opera como uma forma de defesa de outras "versões dos papéis políticos, sociais e culturais das mulheres, que eram bastante diferentes daqueles propostos ou impostos pela mídia tradicional" (Chambers et al., 2004, p. 128). O jornalismo feminista, como um caminho alternativo relevante para as mulheres frente às resistências colocadas pelo jornalismo industrial, permitiu "às mulheres trocar e compartilhar notícias que dificilmente encontrarão lugar nas principais instituições da mídia e desenvolver habilidades jornalísticas e de mídia" (Chambers et al., 2004, p. 128). Chambers et al. (2004) relembram-nos que, historicamente, "os meios de comunicação alternativos das mulheres contribuíram para a evolução da teoria da imprensa, [] pela promulgação de novos princípios, e, às vezes, até mesmo explicitamente articulando novos princípios jornalísticos, inclusive princípios feministas" (p. 128). Escrevendo sobre o movimento feminista brasileiro, Teles (1993) realça a importância dessas publicações como uma forma de rompimento com a narrativa histórica que concedia espaço quase exclusivamente para "acontecimentos de interesse das elites, em que o homem branco é quem sobressai" (p. 12). A autora ainda destaca a relevância da imprensa feminista brasileira no âmbito latino-americano, "um verdadeiro fenômeno", nas suas palavras (p. 158). Vários foram os periódicos que, voltados às mulheres, questionavam os valores sociais vigentes, mas não nos caberá abordar aqui a sua histórica (ver, por exemplo, Bandeira, 2015; Cardoso, 2004; Chambers et al., 2004; Steiner, 2017). Importando-nos pensar a ética do jornalismo feminista, a seguir dirigimos a nossa atenção para epistemologias feministas como possíveis contributos para esta reflexão. 


\section{Epistemologias feministas e(m) novas proposições éticas para ojornalismo}

Para pensar de que forma os ideais éticos do jornalismo possam abarcar valores feministas, podemos buscar inspirações no campo da ética e epistemologia feminista. Uma das teorias que nos parece servir para este fim, como já argumentamos em outro lugar, é a teoria feminista do standpoint, assim como a ética do cuidado, embora originalmente estas tenham sido propostas em um espectro mais amplo e não direcionado para o jornalismo.

Partindo de uma discussão sobre a (não) objetividade na ciência, a teoria do standpoint "define o conhecimento como particular e não universal; abandona o observador neutro da epistemologia modernista; define os sujeitos construídos por forças relacionais como transcendentes" (Hekman, 1997, p. 356). Entendemos seus argumentos centrais podem ser aplicados mais em geral à "busca de conhecimento", uma vez que uma das lições dessa teoria é que a produção de conhecimento inclui o contexto de descoberta e subjetividade, diferente do que vemos no entendimento tradicional do jornalismo. A ideia é a de que iniciar o processo de pensamento e de conhecimento a partir da vida de pessoas e grupos marginalizados induz a fazer perguntas mais críticas e revela mais dos pressupostos não examinados que influenciam os contextos de busca de conhecimento. Assim, entende-se que o ponto de vista da mulher poderia ser emancipatório, por fazer parte de um grupo social oprimido, assim como o ponto de vista de pessoas que fazem parte de outros grupos sociais que são minorias políticas.

O jornalismo, como a ciência, deve atender ao valor da diversidade cognitiva, experiencial e institucional. A mudança proposta é a definição do ponto de vista feminista como conhecimento situado e engajado, "como um lugar a partir do qual as feministas podem articular um discurso contra-hegemônico e defender uma sociedade menos repressiva" (Hekman, 1997, p. 363). Pensando nesta abordagem como uma fonte de reflexão importante para o jornalismo, referimos a Linda Steiner (2018): "ao incorporar contextos tanto da descoberta como da justificação, as suas noções de reflexividade e métodos constituem um recurso prático para jornalistas, proporcionando um jornalismo credível, ético, social e epistemologicamente responsável" (p. 1858).

Pensar na validade dos pontos de vista variados, localizados e específicos, leva-nos a considerar a ética do cuidado como uma fonte importante de reflexão para uma ética feminista nojornalismo, comojá adiantado por outras/os autoras/ es. Diferente de uma ética moral kantiana, universal e abstrata, os julgamentos morais baseados em uma ética do cuidado caracterizam-se como "particulares, contextuais, parciais e fundamentados na emoção" (Friedman, 2013, p. 705).

Ainda que não exista um consenso entre teóricas/os sobre o que é e como deveria ser aplicada uma ética do cuidado, adotamos aqui a perspectiva de uma ética do cuidado crítica, política e que vá além das nossas relações pessoais 
que já envolvem o cuidado (ver Held, 2006; Kittay, 1999). Esta "pode iluminar como as relações causam marginalização, exclusão, opressão e sofrimento" (Friedman, 2013, p. 5) e dedicar atenção a estes pontos de vista, o que se torna ainda mais importante se considerarmos o potencial disruptivo do ponto de vista das populações de alguma forma oprimidas.

Nojornalismo, parece-nos especialmente relevante pensar a ética do cuidado no que tange à valorização do sensível, uma quebra na dualidade entre racional e emocional, objetivo e subjetivo, uma vez que esta perspectiva "reconhece o valor moral dos sentimentos e virtudes baseadas na emoção, como empatia e sensibilidade" (Silveirinha, 2016, p. 134). Dessa forma, podemos problematizar "sobre que ou quem as/os jornalistas devem se importar" (Steiner \& Okrusch, 2006, p. 104). De acordo com Steiner (2008), uma "versão politizada do cuidado exige que a mídia privilegie os problemas, histórias e contra-histórias das populações marginalizadas ou subordinadas, e outras/os que merecem cuidado e compaixão" (p. 447).

É nesta lógica que Camponez (2014) propõe uma aproximação da ética jornalística com uma ética do cuidado baseada em Gilligan (1982), mesmo que sem uma quebra com as noções de objetividade, por entender que contextos organizacionais, econômicos e corporativos afetam também a qualidade do jornalismo. Esta abordagem centrar-se-ia na passagem de "um paradigma centrado na preocupação da legitimidade de quem deve ser escutado para o de, simplesmente, escutar" (Camponez, 2014, p. 115). Este esforço envolve (re) pensar as/os "jornalistas, as fontes, os sujeitos objeto da informação, o público e o próprio jornalismo, enquanto processo dialógico de produção e construção noticiosa e numa perspectiva de responsabilidade na formação da opinião pública" (Camponez, 2014, p. 120).

É também com ligações com a ética do cuidado que Wasserman (2013) propõe uma ética da escuta, centrada no valor da dignidade humana: "Tratar todas as pessoas com dignidade humana significa que elas não devem ser vistas como meios para o fim de um jornalismo adversário [...], mas como fins em si mesmas. Isso implica ouvir as suas histórias" (p. 78). Esta ética da escuta estaria centrada em uma perspectiva de mudança do jornalismo e da sociedade, especialmente ao focar-se na dignidade de pessoas socialmente marginalizadas, trabalhando em uma posição mais próxima da população.

Olhando para os contributos da ética e da teoria feminista, podemos pensar em um jornalismo mais humano, mais responsável e, de fato, mais diverso, tendo maior atenção às populações oprimidas e marginalizadas. Para além disso, considerar as pessoas entrevistadas como fins em si próprias, em vez de apenas como meios para lograr a publicação de uma boa reportagem, faznos repensar o processo de construção dos textos jornalísticos. A partir disso, não há apenas uma abordagem viável, e sim várias, que propõem centralmente rompimentos com a objetividade jornalística tradicional, inclusive em relação à participação social e política das/os jornalistas, que acreditamos ser de suma 
importância para a obtenção de um conteúdo mais responsável, mas também para uma democracia mais participativa.

\section{Jornalismo contra o machismo, pela equidade de gênero: os posicionamentos editoriais das plataformas Revista AzMina e Gênero e Número}

Com estes pontos, acreditamos ter construído uma base teórica que nos permite olhar com maior entendimento para o jornalismo feminista brasileiro contemporâneo. Assim, nos ocuparemos, em seguida, da análise dos estatutos editoriais das plataformas Revista AzMina e Gênero e Número, a fim de ampliar a nossa reflexão teórica com fundamentos da prática.

Alguns critérios foram empregados na seleção dos veículos cujos estatutos editoriais iriam compor o corpus de análise deste estudo: buscamos por iniciativas de jornalismo online independente brasileiras que contivessem termos como feminismo, igualdade ou equidade de gênero no seu posicionamento. Foram selecionadas as plataformas nativas digitais Revista AzMina (AM) e Gênero e Número (GN), ambas presentes no mapeamento de jornalismo independente no Brasil da Agência Pública ${ }^{1}$ e com visibilidade significativa no contexto digital brasileiro, midiático e feminista. ${ }^{2}$ Chamou-nos a atenção que as duas plataformas trabalham frequentemente em colaboração entre si, o que favoreceu a escolha das duas, a fim de entendermos o que as aproxima e distancia, demonstrando possíveis diferenças nos posicionamentos no âmbito do jornalismo feminista.

O corpus de análise é composto, assim, pelos conteúdos disponíveis nas páginas "Quem somos"3 e "Missão, visão e valores" ${ }^{4}$ do site da AM, e "Sobre", do site da GN, adotados como expressão do posicionamento editorial das plataformas, na falta de um estatuto editorial formalizado.

\subsection{Metodologia}

A metodologia adotada nesta pesquisa é a análise textual, uma abordagem que, olhando para os textos, "vai além do conteúdo manifesto para entender as ideologias predominantes de um determinado momento histórico e cultural que tornam possível uma cobertura específica" (Fürsich, 2018). Como defende Fürsich (2009, p. 238), "os textos midiáticos apresentam um momento discursivo distinto, entre a codificação e a decodificação, o que justifica um engajamento

1 Ver https://apublica.org/mapa-do-jornalismo/

2 De acordo com o relatório de atividades da AM de 2016, o site recebeu 2,4 milhões de acessos no ano. Este dado não foi disponibilizado pela GN. Ver https://drive.google.com/file/d/1qfindSOEaLIDtKWQSkAlMyZt5jDEwmtl/view

3 Ver https://azmina.com.br/sobre/quem-somos/

4 Ver https://azmina.com.br/missao-visao-e-valores/

5 Ver http://www.generonumero.media/institucional/ 
acadêmico especial" com a análise textual, que, em si, "pode elucidar a estrutura narrativa, os arranjos simbólicos e o potencial ideológico do conteúdo da mídia” (p. 239). Esta perspectiva metodológica, baseada num posicionamento construcionista, compreende que os textos podem ser interpretados de múltiplas formas e, dessa forma, com uma abordagem indutiva e interpretativa, foca-se na observação e na análise contextual simultaneamente.

\subsection{Análise}

Olhamos, inicialmente, para o estatuto editorial da Revista AzMina (AM). A primeira frase do "Quem somos" da iniciativa, que se define como uma instituição sem fins lucrativos, contém um posicionamento contundente e importante no âmbito das nossas discussões: "Jornalismo, tecnologia e informação contra o machismo". A ideologia da objetividade, adotada no jornalismo tradicional defende que o jornalismo precisa ser isento em relação às questões sociais, econômicas e políticas que aborda, o que se traduz, muitas vezes, em uma abordagem desinteressada dessas questões. Por outro lado, a ideia de que, centralmente, o jornalismo d'AzMina irá se opor ao machismo quebra diretamente com esta lógica, justamente por pautar o seu conteúdo na desconstrução e no combate da opressão de gênero.

Parece-nos interessante pensar neste posicionamento à luz do argumento de Cohen-Almagor (2008), que defende que o jornalismo abandone a objetividade ao tratar de assuntos como terrorismo, racismo, canibalismo, genocídio e escravidão, por exemplo. Acreditamos ser de suma importância que ojornalismo se porte desta maneira também em relação às questões de gênero, como neste posicionamento.

A plataforma define como sua missão a promoção da "equidade de gênero por meio da informação e da educação, considerando especificidades de raças, classe e orientação sexual". Neste ponto, podemos ver que AM entende a sua produção de conteúdo como parte do processo de luta em direção à equidade de gênero. Ainda, ao detalhar que considera as questões de raça, classe e sexualidade, a iniciativa demonstra entendimento de que as opressões de gênero devem ser vistas a partir de uma perspectiva interseccional, uma importante contribuição dos estudos de mulheres negras aos feminismos (Carastathis, 2014) e uma característica marcante do que algumas autoras já argumentam ser uma quarta onda do feminismo no Brasil (Perez \& Ricoldi, 2019). Na prática jornalística, entendemos que ter esta perspectiva interseccional, dentro de um contexto de atenção às questões de gênero, significa pautar as questões das mulheres de forma ampla, destacando outras formas de opressão, como o racismo e o classismo vigentes na sociedade brasileira (e em outras), assim como possivelmente discutir estes temas individualmente.

O estatuto editorial da plataforma lista também os valores que guiam as suas atividades. Destacamos a empatia: "AzMina procura se colocar no lugar do 
outro. Nosso jeito de contar histórias e de difundir o conhecimento passa pela escuta genuína e interessada, reconhecendo a singularidade de cada indivíduo e buscando soluções coletivas". Esta proposição tem fortes ligações com a ética do cuidado (Friedman, 2013), discutida anteriormente, especialmente no que tange à "escuta genuína e interessada". Esta perspectiva também propõe uma quebra com a abordagem objetiva desinteressada. Relembramos, neste ponto, a proposição de Wasserman (Wasserman, 2013) de uma "ética da escuta", ligada justamente à ética do cuidado.

Para mais, o "reconhecer da singularidade de cada indivíduo" serve na defesa de que é válido escutar pessoas múltiplas e destacar as suas experiências, porque qualquer que seja a sua perspectiva, será única. Para Camponez (2014, p. 115), adotar uma ética do cuidado no jornalismo envolve abandonar "um paradigma centrado na preocupação da legitimidade de quem deve se escutado para [adotar] o de, simplesmente, escutar". Isto se conecta com outro dos valores apontados pela AM, o da diversidade: "quanto mais vozes diferentes, mais longe a voz d'AzMina chegará e mais gente se sentirá parte dela. Temos o compromisso de trazer para o debate público vozes de diversas raças, classes, ideologias, orientações sexuais e gêneros". A plataforma compromete-se com o diálogo "como forma de promover a transformação" e ressalta que busca dar espaço a diferentes pontos de vista.

Considerando a crítica de Allan (1998) à política de verdade do jornalismo tradicional - postura que apresenta o conhecimento construído individualmente como verdade absoluta-, o comprometimento para com o diálogo mostra uma abertura para a construção coletiva, ou dialógica, para usar o termo bakhtiniano, do conhecimento.

No que tange ao rigor da produção jornalística da AM, destacamos os valores de "Excelência e responsabilidade na apuração e na transmissão de conteúdo", assim como de "Transparência: Dados e processos abertos e compartilhados sempre". Depreendemos, a partir destes excertos, a seriedade com a qual é levada a produção do conteúdo jornalístico da plataforma. A transparência é uma das estratégias que nos parece mais relevantes para a obtenção de um jornalismo responsável, uma vez que as bases de dados utilizadas podem ser checadas por mais pessoas e, ainda, aplicadas para outros fins.

Pensando neste ponto à luz do que argumenta Glasser (1984), de que a objetividade impossibilita a responsabilidade no jornalismo — "se, por reportagem responsável, queremos referir à disponibilidade por parte da/o repórter de ser responsabilizado por aquilo que é reportado"-, o comprometimento com a apuração $e$ a transmissão do conteúdo e com a transparência dos dados torna-se ainda mais importante.

Parece-nos digno de nota dizer que o texto não refere a palavra "mulheres", optando por pela utilização do conceito de gênero. O conceito de objetividade também não é mencionado. 
Passamos agora para uma leitura do estatuto editorial da Gênero e Número (GN). A plataforma define-se como uma "start-up e organização de mídia independente" que pratica "jornalismo de nicho". O texto afirma que a GN "existe para dar visibilidade a dados e a evidências relevantes para o debate sobre equidade de gênero" através do conteúdo jornalístico, mas não apenas nesta frente, criando também espaço para "formatos diversos para expandir debates e narrativas". A partir do excerto, identificamos que o objetivo da iniciativa está, justamente, em dar visibilidade a dados e evidências, sendo esta a sua contribuição para qualificar o debate. Ao posicionar os "dados e evidências" como objetos externos, que devem receber visibilidade, essa construção remete a uma supervalorização dos fatos, característica da objetividade jornalística. Isto fica mais evidente no seguinte trecho: "A produção jornalística que preza pelos fatos e dados abertos é nosso carro-chefe”. Dessa forma, replica-se a ideia de que existe uma separação entre os fatos, que são valorizados, e opinião, parte de uma série de antagonismos como racionalidade e emoção, objetividade e subjetividade.

Com efeito, a iniciativa não se entende como ativista: "É comum que se confunda esse jornalismo de nicho com ativismo, mas a nossa missão é produzir jornalismo plural e preciso". O nicho, neste caso, seria ojornalismo de dados com atenção ao gênero, com fim de qualificar o debate público. De fato, o destaque aos dados é uma das características centrais do projeto, como diz o próprio nome: Gênero e Número. Sobre o excerto citado, poder-se-ia argumentar que se cria de um antagonismo entre a precisão do conteúdo jornalístico e do conteúdo ativista. Entendemos, entretanto, que esta pode ser uma forma de afirmar-se como um veículo de comunicação mais próximo do âmbito profissional, o que se aproxima da abordagem objetiva mencionada anteriormente. É inevitável relacionar estes apontamentos à concepção de gênero como uma forma de capital simbólico: "onde a feminilidade tem um valor simbólico, uma mulher pode compensar esse sinal negativo adquirindo outras formas de capital: profissional, cultural, econômico ou social" (Djerf-Pierre, 2007, p. 82), "uma mulher" sendo, neste caso, o foco nas questões de gênero, assim como uma equipe constituída quase exclusivamente por mulheres.

Em outros pontos, entretanto, o posicionamento do veículo distancia-se da ideia tradicional da objetividade. É neste sentido que associamos este posicionamento ético com a proposta de objetividade holística de Stephen Ward (2018), que defende que o jornalismo deve ser comprometido com a defesa de uma causa, a de uma democracia igualitária, "que busca equidade o tanto quanto liberdade, defende o estado de direito, protege os direitos das minorias das maiorias intolerantes e encoraja o debate respeitoso" (p. 32). Vemos esta associação especialmente considerando o seguinte trecho: "[a GN] propõe-se a aprofundar temas principalmente relacionados a uma agenda de direitos a partir de dados e de vozes legítimas e comprometidas com o diálogo amplo que a democracia pressupõe". 
Pensar em uma democracia verdadeiramente participativa implica em, entendemos, dar espaço para as pessoas que não são ouvidas hoje, aquelas marginalizadas social, cultural e economicamente, uma referência evidente à ética do cuidado política. Essa atenção às desigualdades também está presente, indiretamente, em outro ponto do estatuto editorial: a diversidade é apontada como um dos "valores que regem o nosso trabalho", assim como a transparência. Esta última é especialmente relevante no contexto de um jornalismo de dados, possibilitando o acesso às informações que baseiam as investigações, como mencionado anteriormente, na análise do estatuto editorial da Revista AzMina.

Também neste caso, ressaltamos a utilização do conceito de "gênero", tanto no nome do projeto como no seu estatuto editorial, sem referenciar nominalmente o direcionamento às mulheres (nem utilizar a palavra mulher ou mulheres) em nenhum ponto do texto.

\section{Considerações finais}

No decorrer deste trabalho, considerando as desigualdades encontradas pelas mulheres no jornalismo tradicional, dirigimos a nossa atenção para o jornalismo alternativo, uma prática marcada pela evidente presença de advocacy. A adoção de um ponto de vista que não será neutro, e que adote valores feministas, parecenos urgente neste sentido, à luz da realidade de opressão das mulheres dentro e fora da profissão.

Através da análise dos estatutos editoriais das plataformas Revista AzMina e Gênero e Número realizada neste estudo, foi possível verificar a presença da defesa da equidade de gênero como centrais a ambas as iniciativas. Os projetos compartilham uma série de características: plataformas de jornalismo independente brasileiras, nativas digitais, que têm a produção de conteúdo voltada para a promoção da equidade de gênero, com valores como diversidade e transparência.

Talvez em razão desta similaridade, a AM e a GN colaboram em reportagens construídas em parceria e republicam conteúdo mutuamente, como nos permitiu ver uma rápida busca pelos sites dasiniciativas. Parece-nosinteressante pontuar este movimento como uma quebra com a lógica da competitividade patente no jornalismo tradicional em duas frentes: primeiramente, como iniciativas independentes e sem uma lógica comercial, a colaboração torna-se possível; depois, a partir de um ponto de vista feminista, da ética do cuidado, a interdependência das iniciativas, que caminham para um objetivo comum, vista de uma forma positiva, leva à colaboração. A partir da teoria do standpoint feminista, apontamos ainda para a relevância de diversificar os pontos de vista que estão em contato no âmbito da produção dos conteúdos jornalísticos.

No entanto, como vimos, os seus estatutos editoriais, ainda que se aproximem em algumas características, carregam posicionamentos éticos diferentes. A GN distancia-se do ativismo, firmando-se como um "jornalismo 
de nicho", o que podemos enquadrar como uma forma de advocacy feminista no jornalismo. Foi possível verificar, no texto analisado, uma aproximação da lógica da objetividade tradicional, especialmente na valorização dos fatos e das evidências, como em oposição aos valores ou à subjetividade. No entanto, é possível pensar em outras formas de objetividade, como refere Ward (2009), com efeito, acreditamos ter percebido uma aproximação do posicionamento da plataforma com uma ressignificação importante desta postura, principalmente no que tange ao rompimento com dualismos hoje vigentes, passando para uma visão mais holística e que visa o aprimoramento das democracias participativas. No nosso entendimento, não é possível distanciar este objetivo da inclusão das mulheres, sendo esta também uma postura importante no aprimoramento e aprofundamento do debate sobre a equidade de gênero, como afirma a missão da iniciativa.

Seguindo outra linha, a AM posiciona-se diretamente "contra o machismo", tendo como missão a promoção da equidade de gênero, em uma posição mais ativista. Foi possível perceber um forte distanciamento da norma moral da objetividade, afirmando, entretanto, o rigor informativo necessário para a obtenção de um jornalismo efetivamente responsável. Os valores presentes nos textos analisados, especialmente de diversidade, empatia e da escuta, remetem-nos às epistemologias feministas abordadas no nosso marco teórico, demonstrando, talvez, uma outra forma de ressignificar da ética a partir de princípios feministas.

Ao falarmos do jornalismo alternativo, referimos a um universo vasto, que difere em variadas formas do jornalismo mainstream, se utilizarmos este como padrão de comparação. É evidente, dessa forma, a existência uma um amplo leque de temas a serem cobertos e condutas, o que também se aplica ao jornalismo feminista, como vimos aqui. Os diferentes posicionamentos das plataformas analisadas demonstram que existe uma panóplia de possibilidades de abordagens que levam em conta as desigualdades de gênero e as intersecções das opressões (Carastathis, 2014), sem recair nas noções falhas da ética profissional da objetividade tradicional. Com efeito, faz-se necessário aprofundar as pesquisas nesta área, inclusive para que se amplie o conceito normativo de jornalismo.

\section{Referências bibliográficas}

Acker, J. (1998). The future of "gender and organizations": connections and boundaries. Gender, Work and Organization, 5(4), 195-206. doi:10.1111/1468-0432.00057

Allan, S. (1998). (En)gendering the truth politics of news discourse. In News, gender and power, 121-141. Routledge. doi:10.4324/9780203010631-15

Atton, C. (2003). What is "alternative" journalism? In Journalism. 4(3), 267-272. doi:10.1177/14648849030043001

Atton, C. (2009). Why alternative journalism matters. Journalism, 10(3), 283-285. https:// doi.org/10.1177/1464884909102582 
Bandeira, A. P. B. da S. (2015). Jornalismo feminino e jornalismo feminista: aproximações e distanciamentos. Vozes \& Diálogo, 14(2), 190-199. doi:10.14210/vd.v14no2.p\%25p

Beauvoir, S. de (2016 [1959]). O segundo sexo:fatos e mitos. 3ra ed. Nova Fronteira.

Camponez, C. (2014). Entre verdade e respeito. Por uma ética do cuidado no jornalismo. Comunicação e Sociedade, 25, 110-123. doi:10.17231/comsoc.25(2014).1863

Carastathis, A. (2014). The concept of intersectionality in feminist theory. Philosophy Compass, 9(5), 304-314. doi:10.1111/phc3.12129

Cardoso, E. (2004). Imprensa feminista brasileira pós-1974. Revista Estudos Feministas, 12(spe), 37-55. doi:10.159o/s0104-026×2004000300004

Chambers, D., Steiner, L., \& Fleming, C. (2004). Women and journalism. Londres: Routledge.

Cohen-Almagor, R. (2008). The limits of objective reporting. Journal of Language and Politics, 7(1), 136-155. doi:10.1075/jlp.7.1.07alm

De Vuyst, S., \& Raeymaeckers, K. (2019). Gender as a multi-layered issue in journalism: A multi-method approach to studying barriers sustaining gender inequality in Belgian newsrooms. European Journal of Women's Studies, 26(1), 23-38. doi:10.1177/1350506817729856

Ferrier, M. (2018). Attacks and Harassment: The Impact on Female Journalists and Their Reporting. Recuperado de https://www.iwmf.org/wp-content/uploads/2018/og/ Attacks-and-Harassment.pdf

Friedman, M. (2013). Care Ethics. In The International Encyclopedia of Ethics (pp. 705-713). Blackwell Publishing Ltd. Published. doi:10.4324/9781315873350

Fürsich, E. (2009). In defense of textual analysis: Restoring a challenged method for journalism and media studies. Journalism Studies, 10(2), 238-252. doi:10.1080/14616700802374050

Fürsich, E. (2018). Textual Analysis and Communication. Oxford Bibliographies. doi:10.1093/ OBO/9780199756841-0216

[Autora]. (2020).

Geertsema Sligh, M. (2018). Gender Issues in News Coverage. In The International Encyclopedia of Journalism Studies, 1-8. Wiley. doi:10.1002/9781118841570.iejso162

Gilligan, C. (1982). In A Different Voice: Psychological Theory and Women's Development. Harvard University Press.

Glasser, T. T. (1984). Objectivity Precludes Responsibility. The Quill, 72(2). Recuperado de http://www.columbia.edu/itc/journalism/j6075/edit/readings/glasser.html

Gomes Barbosa, K., \& Varão, R. (2018). Error, Doubt and Gendered Journalism: A Look at the Rape Coverage in the Feature "A Rape On Campus". Brazilian Journalism Research, 14(1), 12-29. doi:10.25200/bjr.v14n1.2018.1049

Harcup, T. (2003). "The unspoken - Said": The journalism of alternative media. Journalism, 4(3), 356-376. doi:10.1177/14648849030043006

Hekman, S. (1997). Truth and Method: Feminist Standpoint Theory Revisited. Signs, 22(2), 341-365. Recuperado de https://www.jstor.org/stable/3175275

Held, V. (2006). The Ethics of Care: Personal, Political, and Global. Oxford University Press.

Jenkins, J., \& Finneman, T. (2018). Gender trouble in the workplace: applying Judith Butler's theory of performativity to news organizations. Feminist Media Studies, 18(2), 157-172. doi:10.1080/14680777.2017.1308412

Kittay, E. (1999). Love's Labor: Essays on Women, Equality, and Dependency. Routledge.

Lelo, T. V. (2019). A feminização do jornalismo sob a ótica das desigualdades de gênero. Revista Estudos Feministas, 27(2), 1-14. doi:10.159o/1806-9584-2019v27n254225 
Lobo, P., Silveirinha, M. J., Torres da Silva, M., \& Subtil, F. (2017). “In Journalism, We Are All Men": Material voices in the production of gender meanings. Journalism Studies, 18(9), 1148-1166. doi:10.1080/1461670X.2015.1111161

Macharia, S. (2015). Global Media Monitoring Project 2015. doi:10.1002/9781119429128. iegmco74

Mahtani, M. (2005). Gendered news practices: examining experiences of women journalists in different national contexts. In S. Allan (Org.), Journalism: Critical Issues (pp. 299-310). Open University Press.

Muñoz-Torres, J. R. (2012). Truth and objectivity in journalism: Anatomy of an endless misunderstanding. Journalism Studies, 13(4), 566-582. doi:10.1080/1461670X.2012.662401

North, L. (2009). Gendered experiences of industry change and the effects of neoliberalism. Journalism Studies, 10(4), 506-521. doi:10.1080/14616700902783911

Perez, O. C., \& Ricoldi, A. M. (2019, agosto). A Quarta Onda Feminista: Interseccional, Digital E Coletiva. X Congresso Latino-americano de Ciência Política. Recuperado de https:// alacip.org/cong19/25-perez-19.pdf

Pontes, F. S. (2017). Desigualdades estruturais de gênero no trabalho jornalístico: o perfil das jornalistas brasileiras. E-Compós, 20(1), 1-15. doi:10.30962/ec.1310

Ross, K. (2001). Women at Work: Journalism as en-gendered practice. Journalism Studies, 2(4), 531-544. doi:10.1080/14616700120086404

Ruoho, I., \& Torkkola, S. (2018). Journalism and Gender: Toward a Multidimensional Approach. Nordicom Review, 39, 67-79. doi:10.2478/nor-2018-0002.67

Schudson, M. (2001). The objectivity norm in American journalism. Journalism, 2(2), 149170. doi:10.1177/146488490100200201

Silveirinha, M. J. (2016). Sensitive to others: emotions, care and gender in the construction of news. In C. Cerqueira, R. Cabecinhas, \& S. I. Magalhães (Orgs.), Gender in focus: (new) trends in media (pp. 125-140). Centro de Estudos de Comunicação e Sociedade (CECS).

Silveirinha, M. J., \& Simões, R. B. de. (2016). As mulheres tentam compensar. O verbo «compensar» é terrível, não é? Género e jornalismo em tempos de mudança. Ex aequo. Revista da Associação Portuguesa de Estudos sobre as Mulheres, 33, 31-47. doi:10.22355/ exaequo.2016.33.03

Steiner, L. (2008). Feminist Media Ethics. In L. Wilkins, \& C. Christians (Orgs.), The Routledge Handbook of Mass Media Ethics (pp. 433-452). Londres: Routledge.

Steiner, L. (2017). Gender and Journalism. Oxford Research Encyclopedia of Communication, December, 1-23. doi:1093/acrefore/9780190228613.013.91

Steiner, L. (2018). Solving Journalism's Post-Truth Crisis With Feminist Standpoint Epistemology. Journalism Studies, 19(13), 1854-1865. doi:10.1080/1461670X.2018.1498749

Steiner, L. (2019). Feminist Journalism. In T. P. Vos, \& F. Hanusch (Orgs.), The International Encyclopedia of Journalism Studies (pp. 1-9). Wiley. doi: 10.1002/9781118841570.iejso130

Steiner, L., \& Okrusch, C. (2006). Care As a Virtue for Journalists. Journal of Mass Media Ethics, 21(2), 102-122. doi:10.1207/s15327728jmme2102\&3_2

Teles, M. A. de A. (1993). Breve história do feminismo no Brasil. Brasiliense.

Tuchman, G. (1972). Objectivity as Strategic Ritual: An Examination of Newsmen's Notions of Objectivity. American Journal of Sociology, 77(4), 66o-679. doi:10.4324/9781315189772-9

Ward, S. J. A. (2009). Journalism ethics. In K. H. T. Wahl-Jorgensen (Org.), The Handbook of Journalism Studies (pp. 295-309). Taylor and Francis. doi:10.4324/9780203877685-31

Ward, S. J. A. (2018). Disrupting journalism ethics: Radical change on the frontier of digital media. doi:10.4324/9781315179377 
Wasserman, H. (2013). Journalism in a new democracy: The ethics of listening. Communicatio, 39(1), 67-84, doi: 10.1080/02500167.2013.772217

Westerståhl, J. (1983). Objective news reporting: General Premises. Communication Research, 10(3), 403-424. doi:10.1177/009365083010003007

World Economic Forum. (2020). Global Gender Gap Report 2020: Insight Report. doi:10.1002/9781119085621.wbefs3 
